\title{
Synthesis of Layered Octadecyltrimethylammonium- Templated Aluminosilicate and its Use as a Thickening Agentfor Lubricating Grease
}

\section{Lukun Han}

Taiyuan University of Technology

\section{Wenxing Niu}

Taiyuan University of Technology

\section{Xinrui Zhao}

Taiyuan University of Technology

\section{Hong Xu}

Taiyuan University of Technology

Jinxiang Dong ( $\nabla$ dongjinxiangwork@hotmail.com )

Taiyuan University of Technology https://orcid.org/0000-0001-5623-3514

\section{Research Article}

Keywords: octadecyltrimethylammonium-templated aluminosilicate, thickening agent, rheology, lubrication

Posted Date: June 10th, 2021

DOl: https://doi.org/10.21203/rs.3.rs-593309/v1

License: (c) (1) This work is licensed under a Creative Commons Attribution 4.0 International License. Read Full License 


\section{Abstract}

We describe herein the use of octadecyltrimethylammonium-templated aluminosilicate (designated as LS) as a thickener to induce gelation. LS samples with different aluminum/silicon molar ratios ( $\mathrm{Al} / \mathrm{Si}=0$, $0.05,0.10,0.15,0.20$ ) were synthesized hydrothermally and characterized by X-ray diffraction analysis, 27AI MAS NMR spectra, elemental analysis, and scanning electron microscopy. The aluminum/silicon molar ratio was shown to be an important factor affecting the rheological properties of LS gels. With increasing Al/Si molar ratio, the viscoelasticity and structural strength of LS gel were enhanced, the dropping point increased, and the amount of oil separation decreased. LS(0.20) gel exhibited superior relative elastic character. The strength of the $L S(0.20)$ gel was also enhanced with increasing $\operatorname{LS}(0.20)$ content. In SRV tests, LS(0.20) gel with different contents showed good performance in terms of loadbearing ability and anti-wear property, indicating that LS was strongly adhered on the friction surface, and thereby promoted lubrication. Owing to simple preparation, the promising rheological and tribological properties, LS gel hold great potential application in lubricating grease.

\section{Full-text}

Due to technical limitations, full-text HTML conversion of this manuscript could not be completed. However, the manuscript can be downloaded and accessed as a PDF.

\section{Figures}




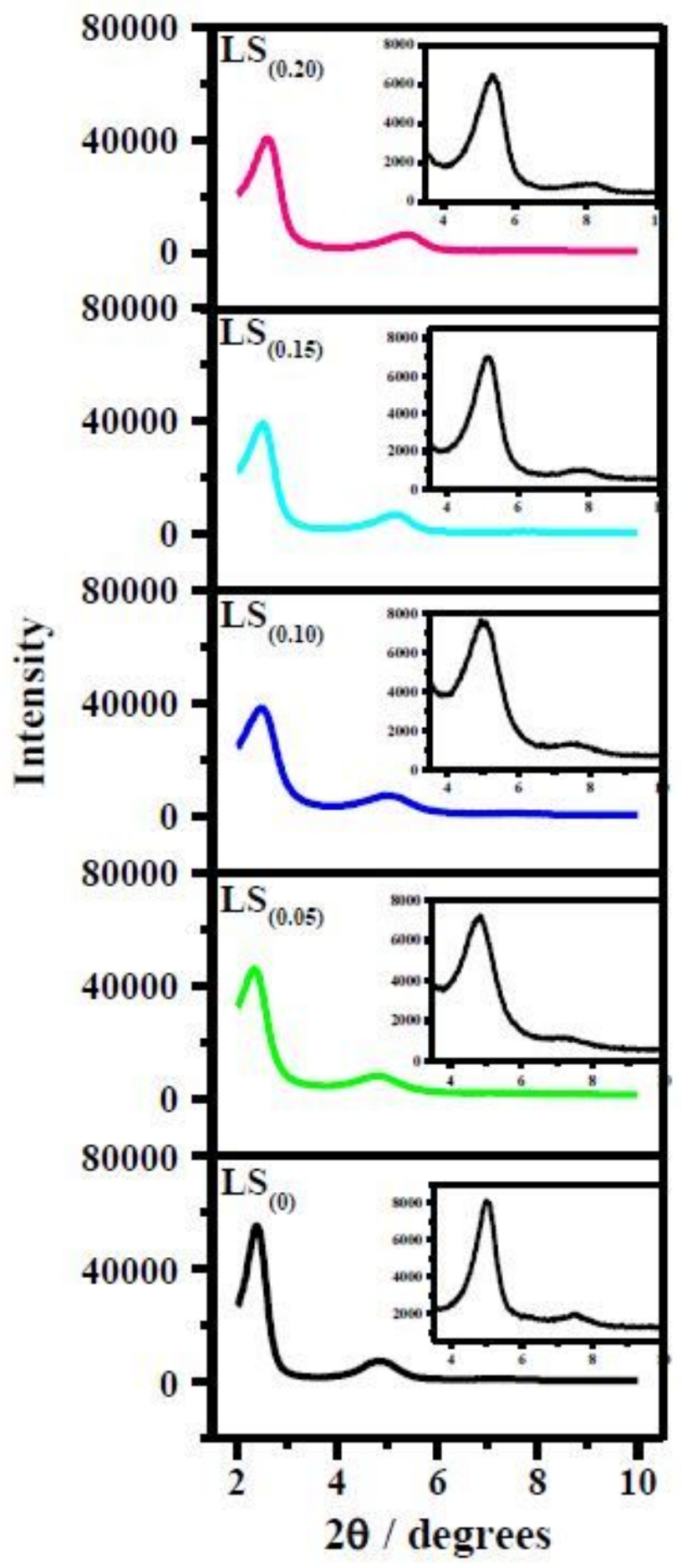

Figure 1

XRD patterns of LS with different Al/Si molar ratios. 

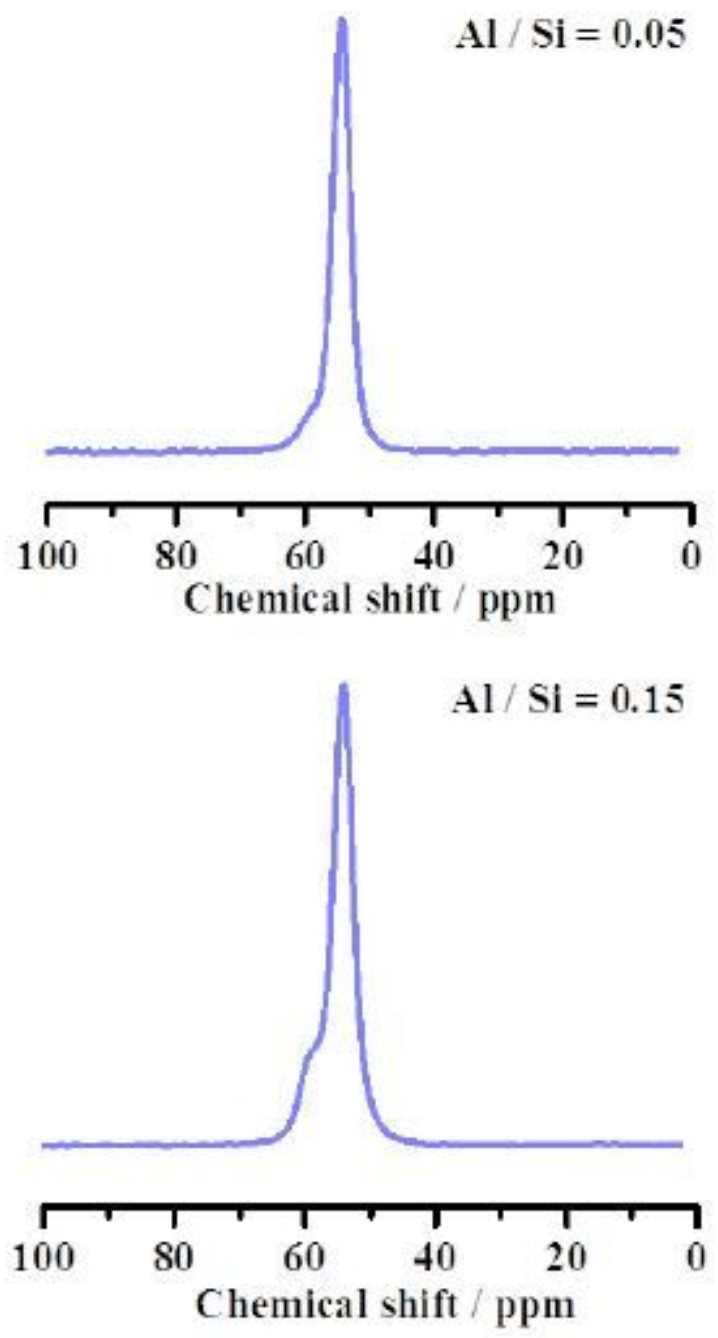
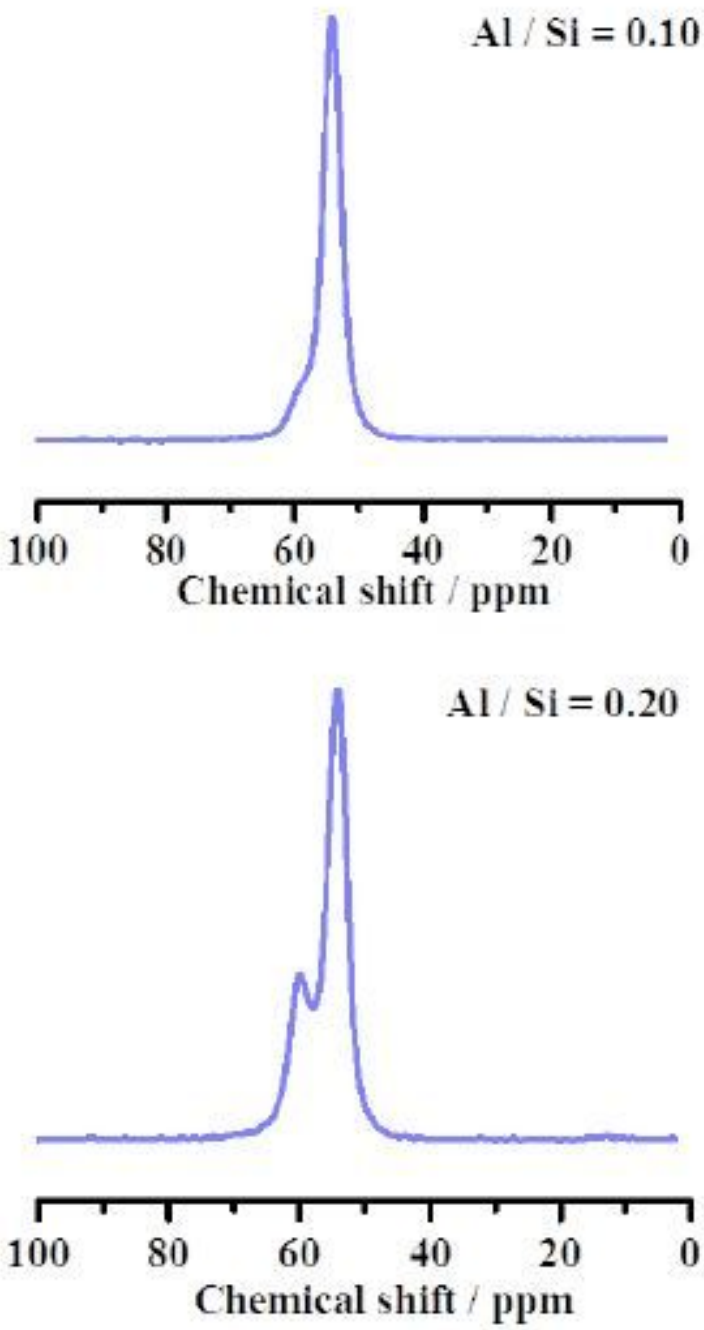

Figure 2

27AI MAS NMR spectra of LS with different Al/Si molar ratios. 


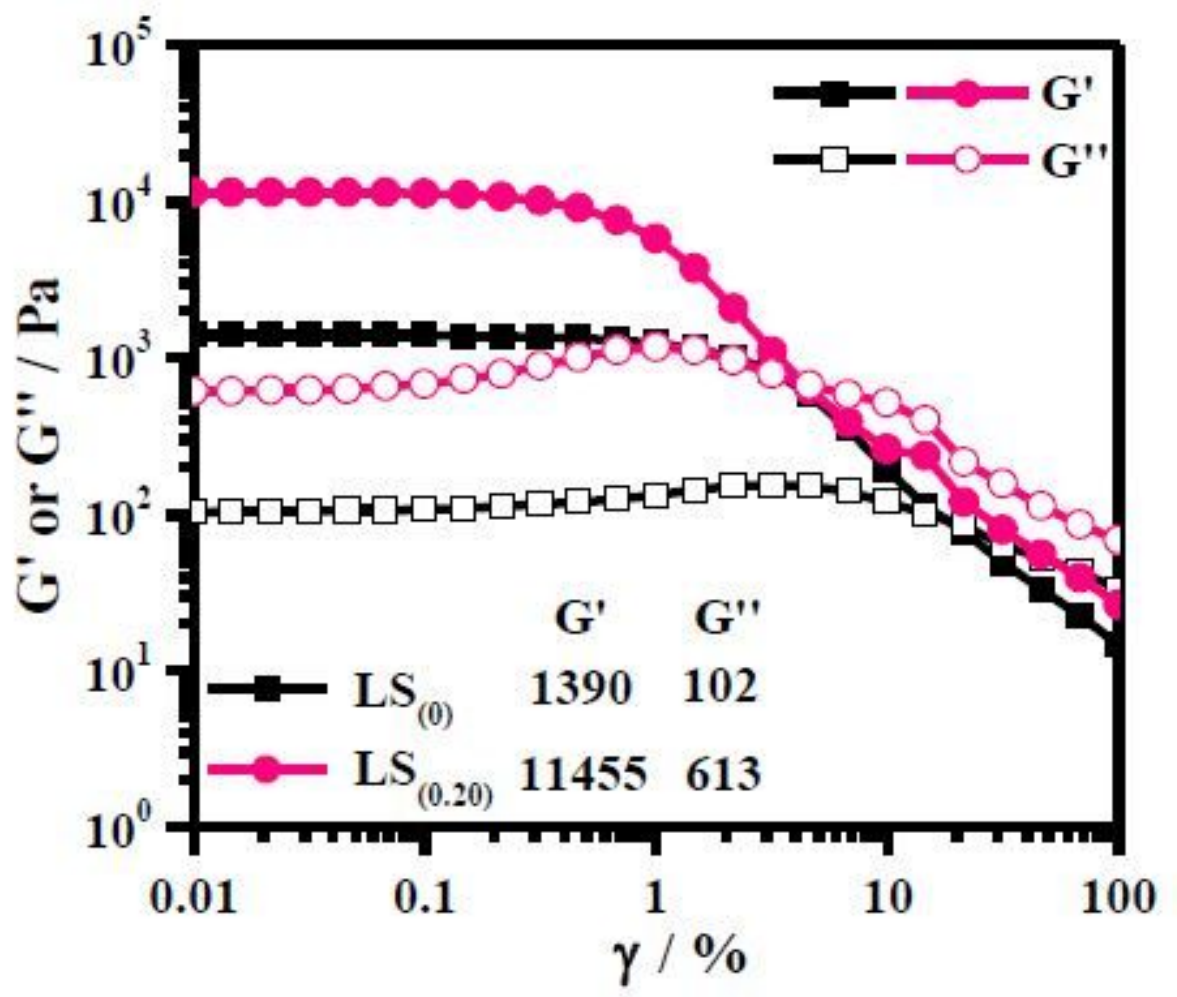

Figure 3

Modulus curves of LS(0) gel and LS(0.20) gel.
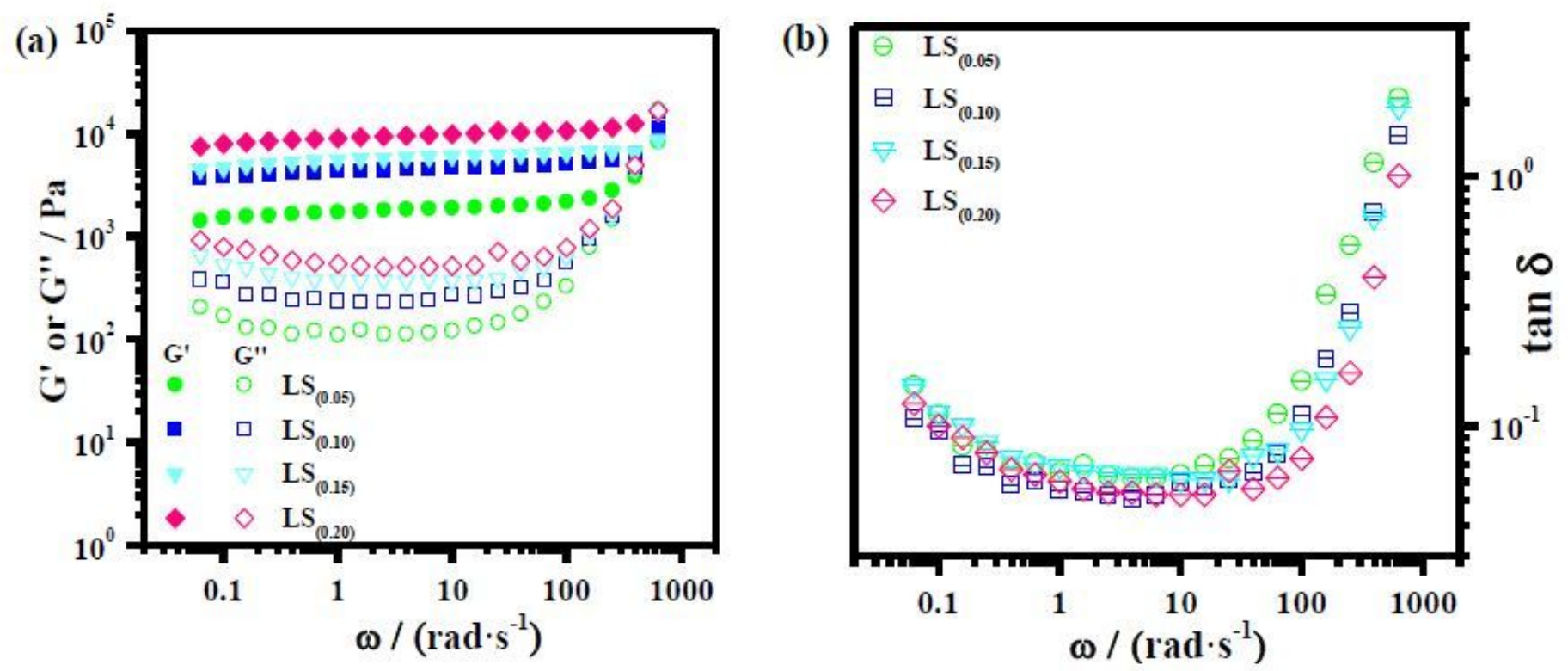

Figure 4

Evolution of the storage and loss moduli (a) and tan $\delta$ (b) with frequency for 20 wt.\% LS gels with different Al/Si molar ratios. 


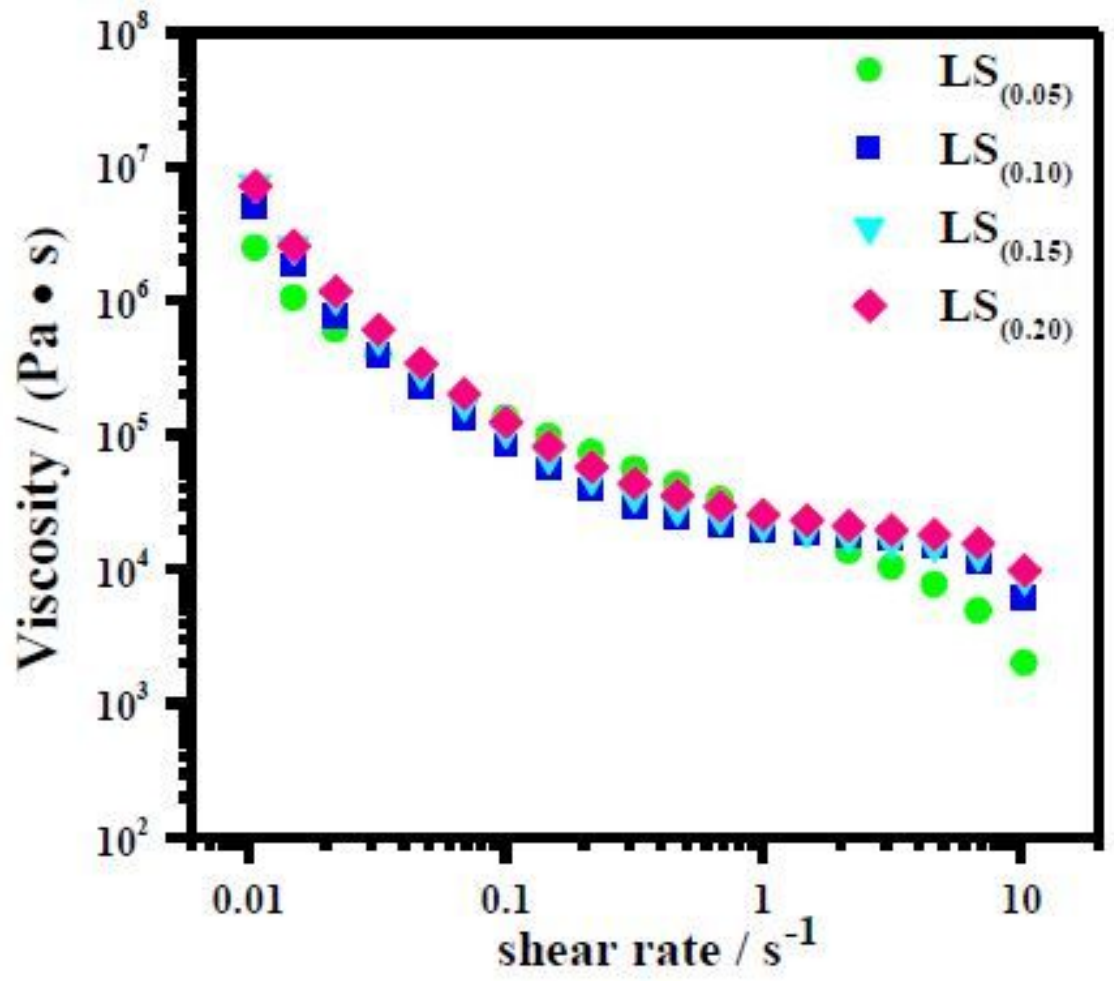

Figure 5

Viscosity curves of 20 wt.\% LS gels with different Al/Si molar ratios.

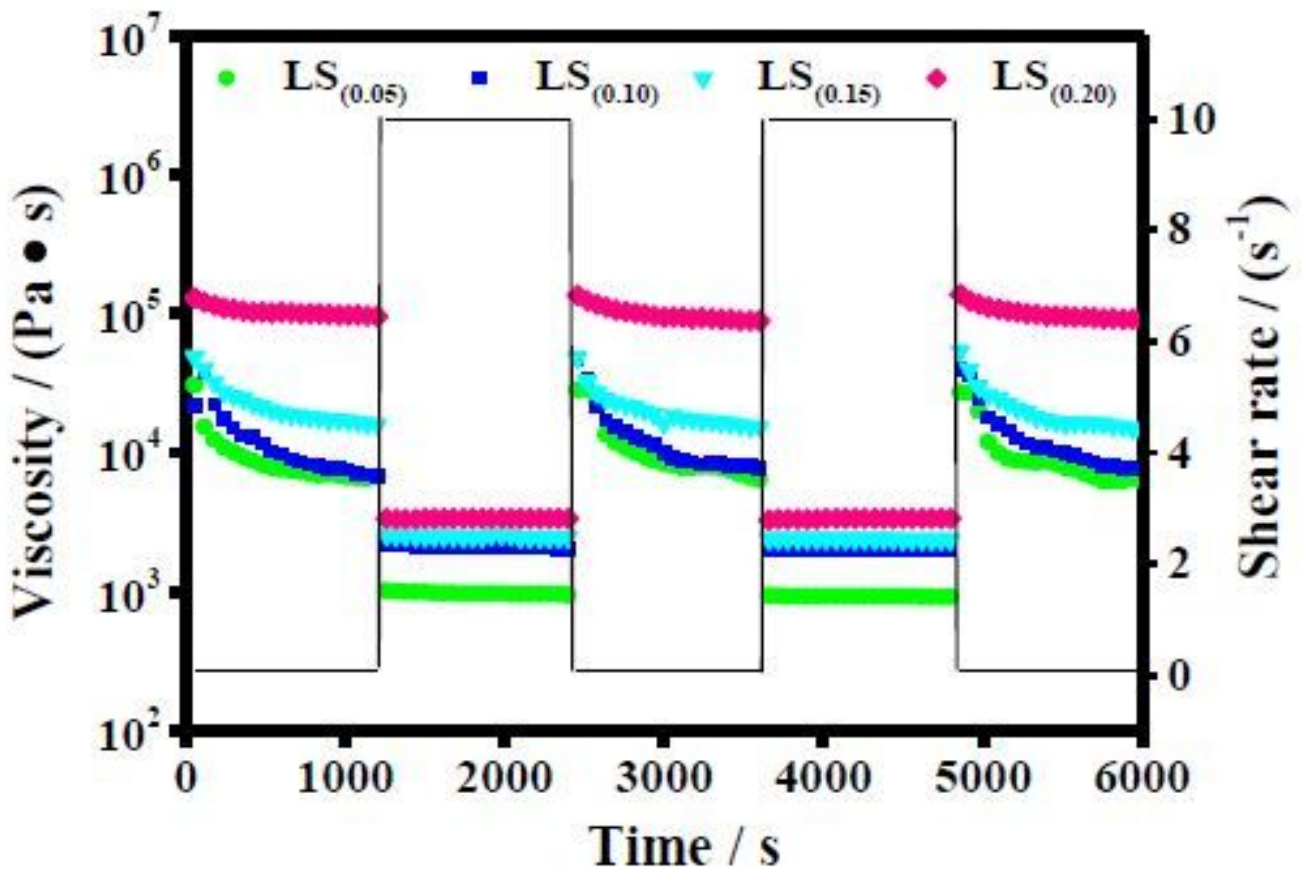

Figure 6 
Thixotropic properties of $20 \mathrm{wt} . \%$ LS gels with different Al/Si molar ratios.

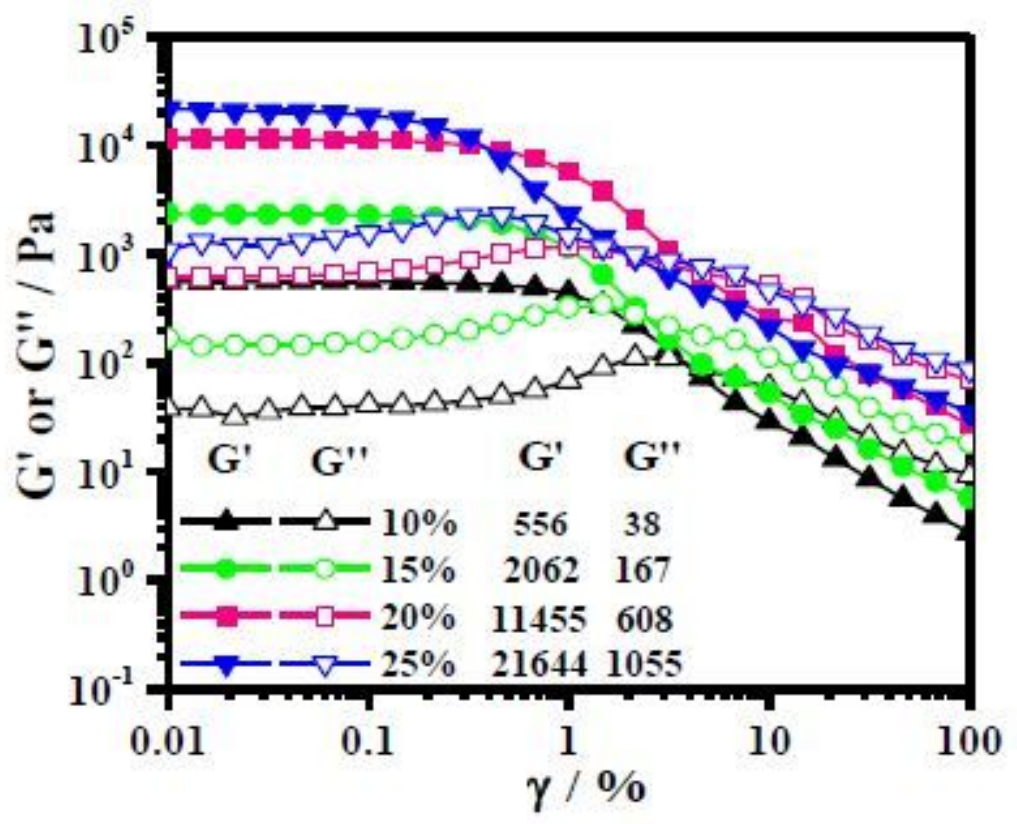

Figure 7

Modulus curves for LS(0.20) gels with different LS(0.20) contents.
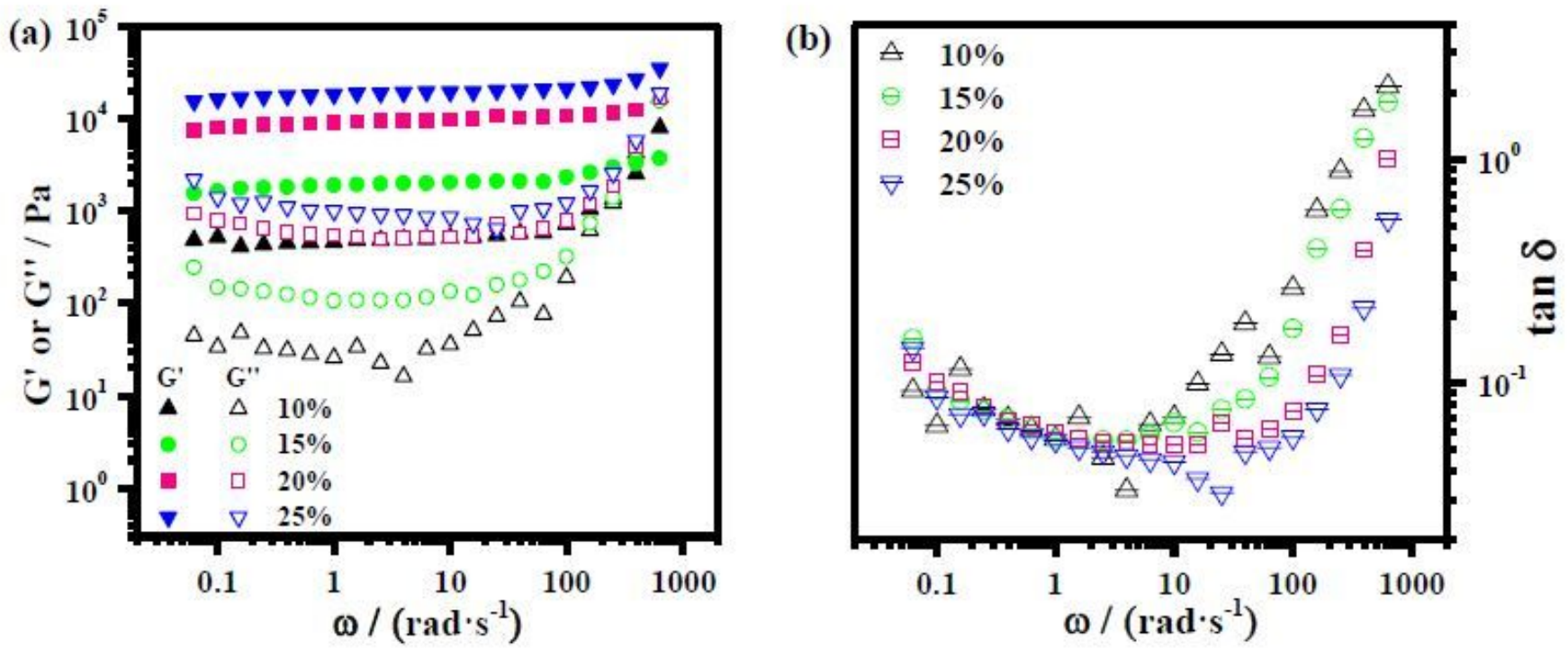

Figure 8

Evolution of the storage and loss moduli (a) and tand (b) with frequency for LS(0.20) gels with different LS(0.20) contents. 


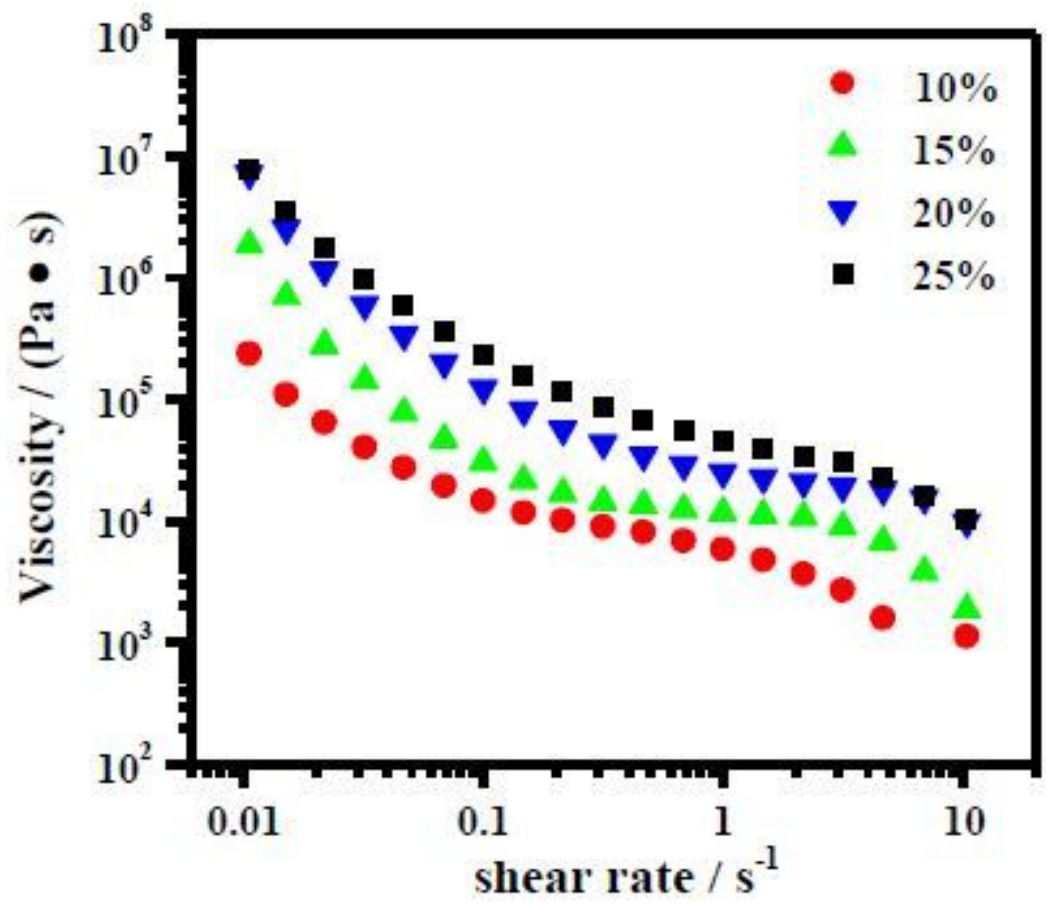

Figure 9

Viscosity curves of LS(0.20) gels with different LS(0.20) contents.

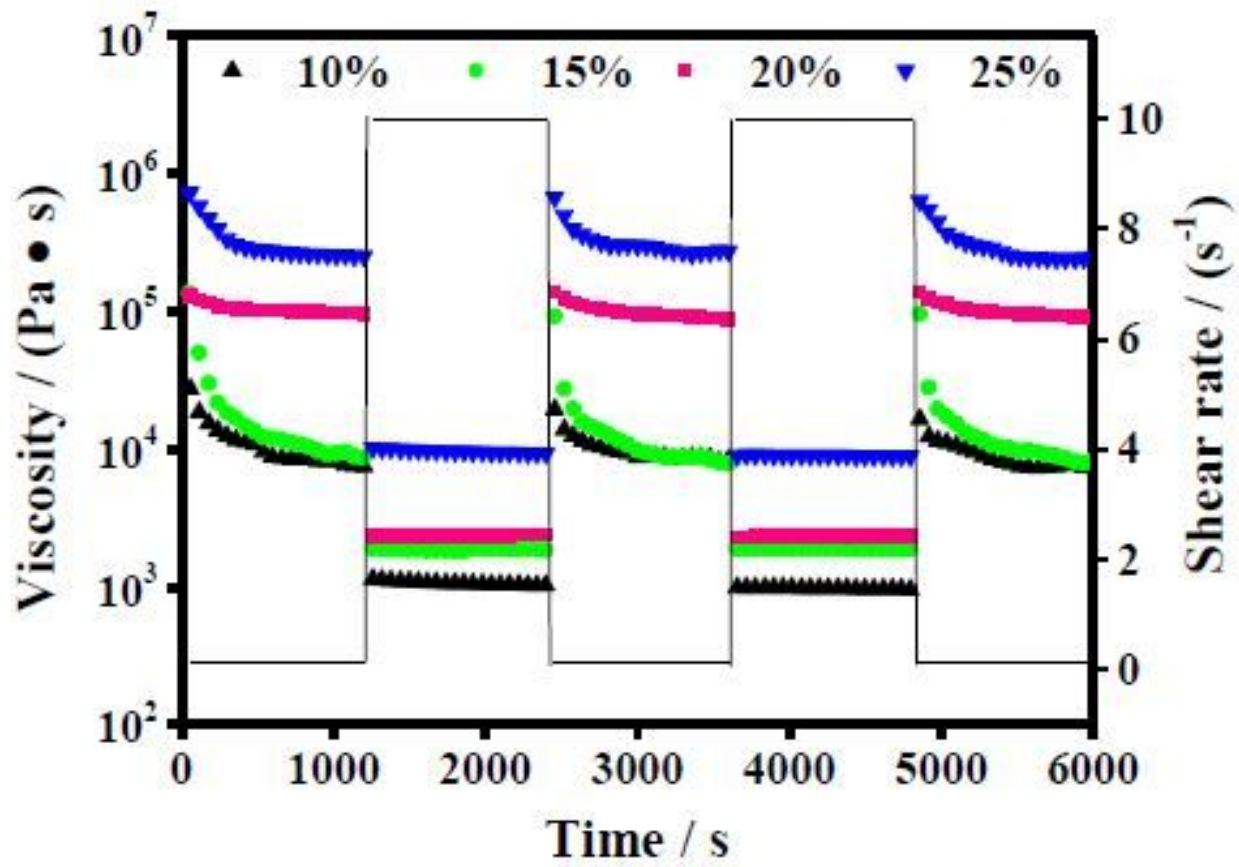

Figure 10

Thixotropic properties of LS(0.20) gels with different LS(0.20) contents. 


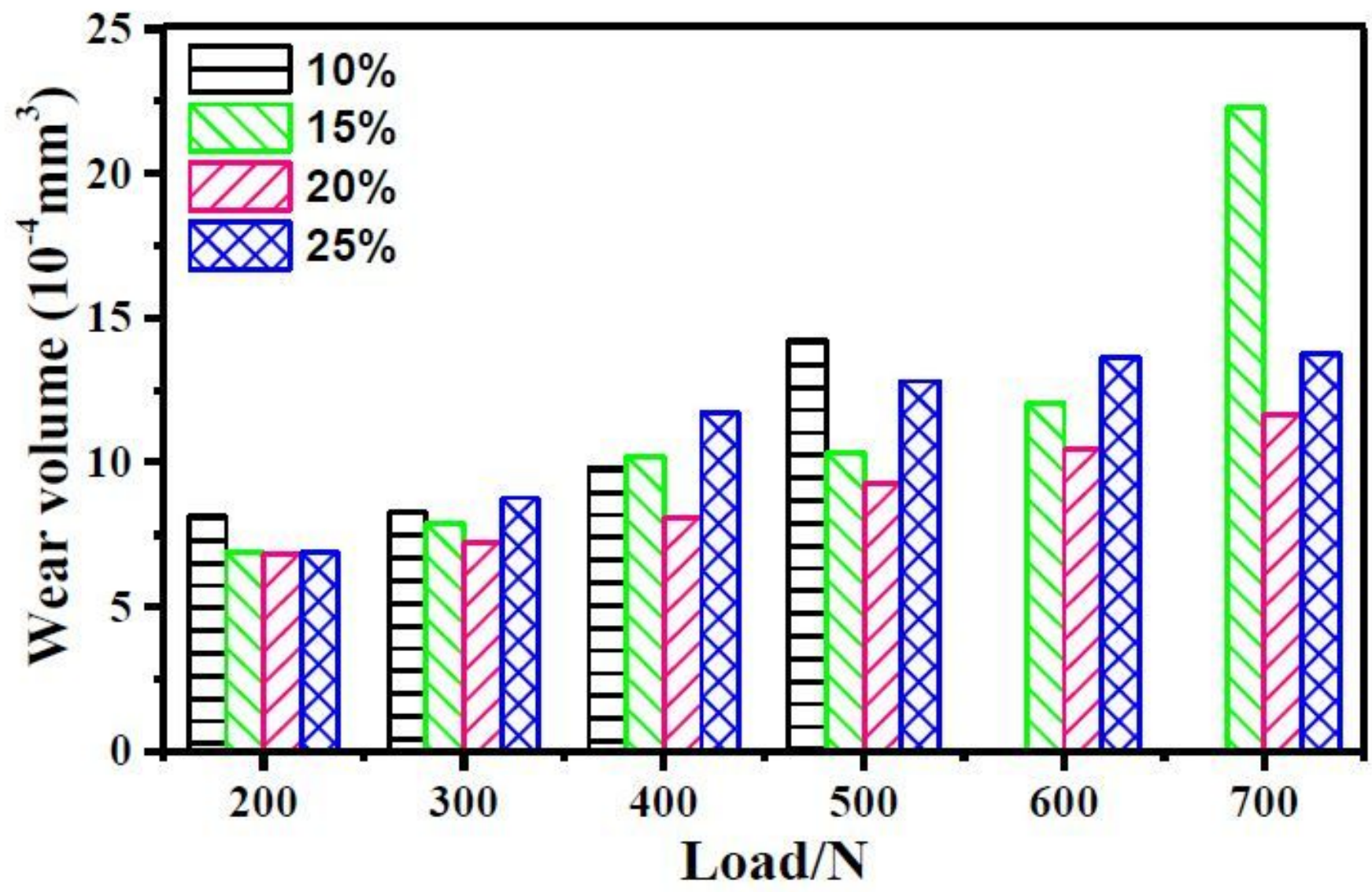

Figure 11

Variation in wear volumes with applied load for each LS gel.
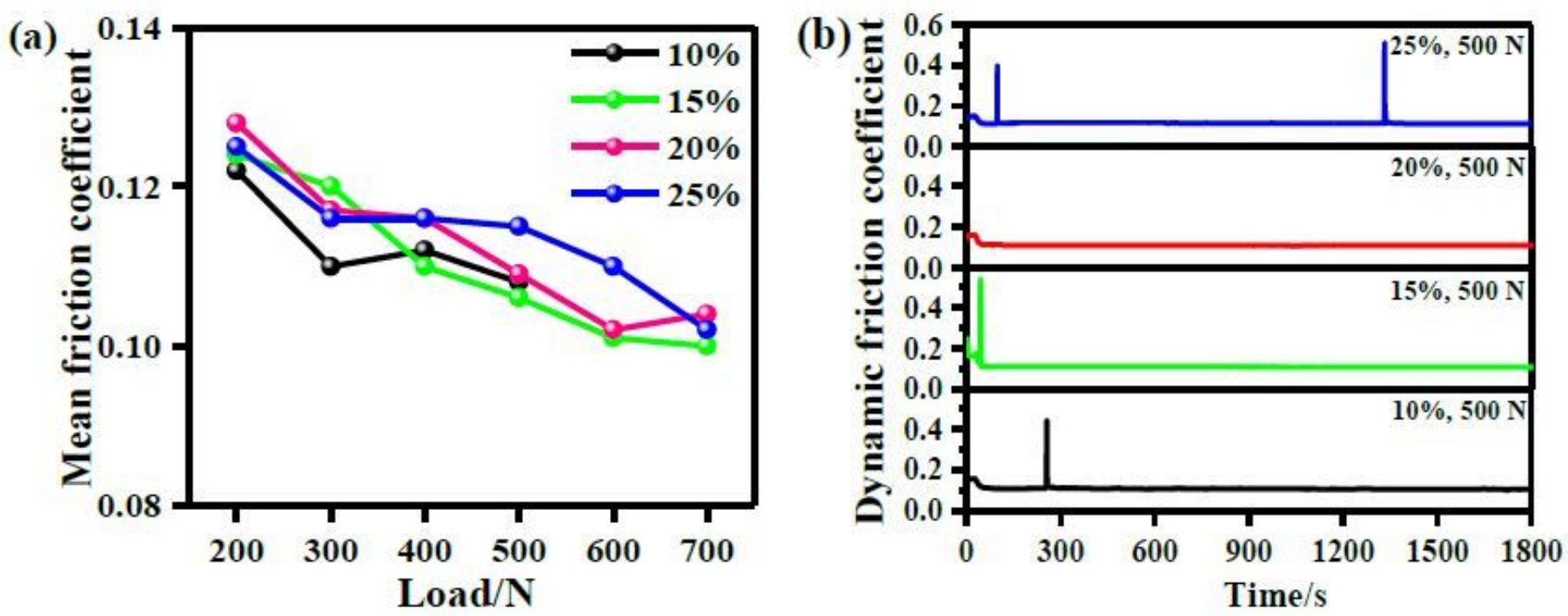

Figure 12

Variation in the mean friction coefficient with applied load (a) and dynamic friction coefficient for each LS gel under $500 \mathrm{~N}(\mathrm{~b})$. 

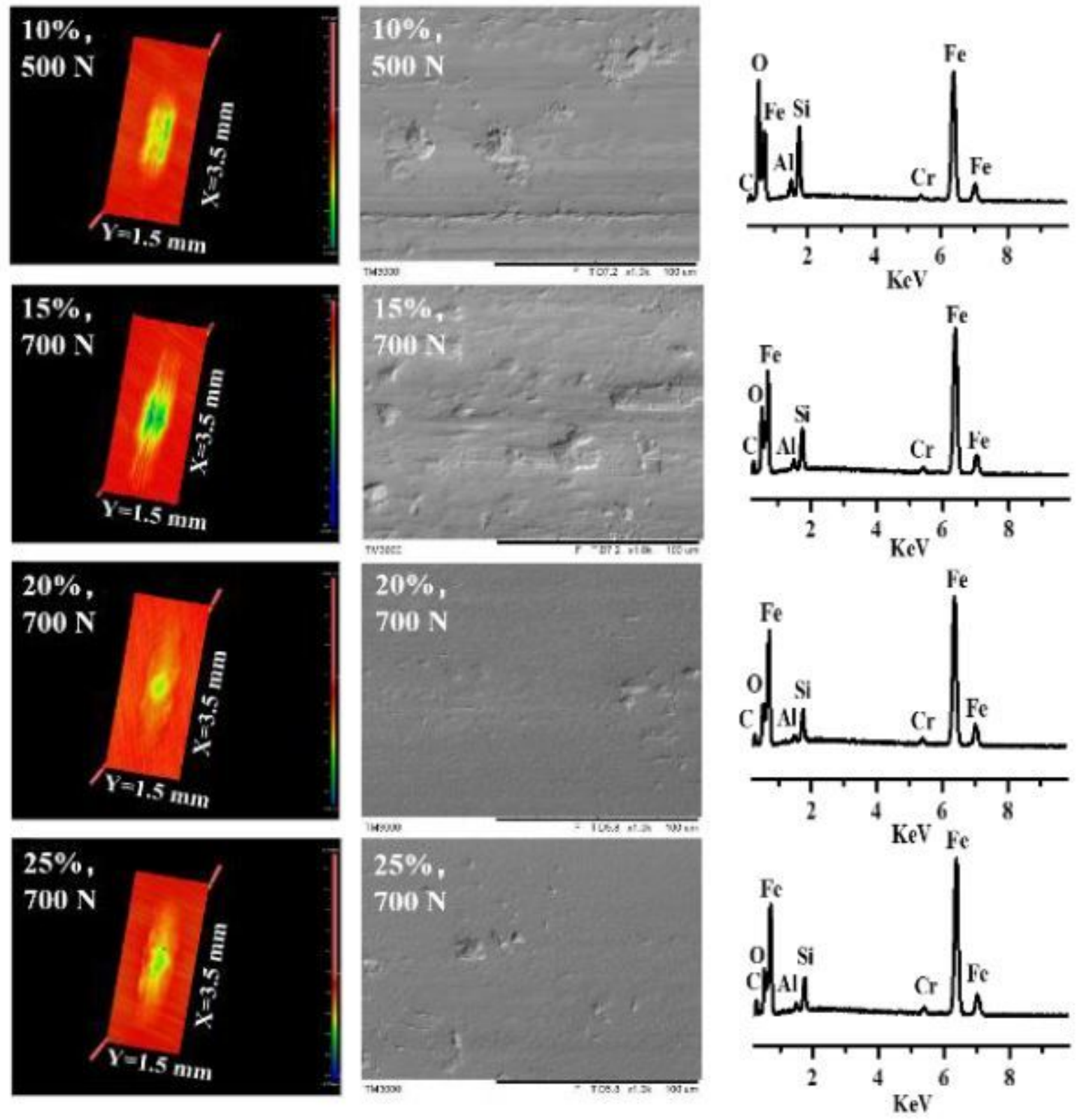

Figure 13

SEM, 3D images, and EDS analysis of steel disc tracks for each LS gel under its highest applied load.

\section{Supplementary Files}

This is a list of supplementary files associated with this preprint. Click to download.

- graphicalabstract.tif

- SupportingInformation.pdf 